\title{
Innervation of copepod antennules investigated using laser scanning confocal microscopy
}

\author{
M. H. Bundy, G.-A. Paffenhöfer \\ Skidaway Institute of Oceanography, Box 13687, Savannah, Georgia 31416, USA
}

\begin{abstract}
The antennules of calanoid copepods compose one of the primary organs for remote sensing of mechanical and chemical environmental stimuli. To better understand how these sensory structures interface with the 3-dimensional fluid environment, it is necessary to understand both their functional morphology and their physiology. These appendages possess setae which are the suspected sites of signal transduction. Ultrastructural studies reveal that the setae differ in their patterns of innervation, and it is believed that these dissimilarities reflect differences in function. In this study, we label the sensilla of copepod antennules using a fluorescent carbocyanine dye, DiI, which becomes inserted in the lipid bilayer of neuronal cell membranes. Aesthetascs on the antennules can then be identified using standard fluorescent microscopy. Because the copepod exoskeleton is transparent to the laser, we were able to utilize laser scanning confocal microscopy to identify other neuronal structures and patterns of musculature within the antennule, while simultaneously visualizing the orientation and larger scale structure of the sensilla.
\end{abstract}

KEY WORDS: Confocal microscopy $\cdot$ Copepod antennae $\cdot$ Sensory physiology

\section{INTRODUCTION}

Feeding studies and visual observations show that copepods have the ability to recognize food particles, mates, potential predators and dissolved substances without physically contacting the source of the stimulus (Katona 1973, Strickler \& Twombly 1975, Poulet \& Marsot 1980, Folt \& Goldman 1981, Poulet \& Ouellet 1982, Buskey 1984, Price \& Paffenhöfer 1985, Huntley et al. 1986, Van Alstyne 1986, Uchima \& Murano 1988, Uye \& Takamatsu 1990). The most likely sensory structures involved in the remote detection of chemical and hydrodynamic stimuli are the setae of the antennules (first antennae) and the mouthparts (Strickler \& Bal 1973, Gill \& Crisp 1985, Price \& Paffenhöfer 1985, Gill 1986). The morphology and physiology of sensory structures are constrained by the necessity of efficiently interfacing with the environment (Atema 1985). Therefore, it is important to examine not only the ultrastructure and physiology of copepod sensory structures, but to also determine the ways in which these structures physically interface with environmental stimuli.
Several investigations of neuronal organization and structure have used cellular markers to trace neurons in living and preserved arthropod tissue. Mellon \& Munger (1990) used tritiated L-leucine to examine the projection of olfactory neurons from crayfish chemoreceptive antennular sensilla to the olfactory labes of the brain. Their technique involved sectioning the tissue, coating the sections with a photosensitive emulsion and processing the sections for autoradiography, a process which takes several weeks. Heimann (1984) utilized transmission electron microscopy (TEM) and scanning electron microscopy (SEM) to investigate the ultrastructure of aesthetascs on the antennules of the isopod Asellus aquaticus. He used methylene blue and lanthanum nitrate as tracers to determine the permeability of the sensilla. Other markers such as horseradish peroxidase, Lucifer yellow or Procion yellow can be injected using a microelectrode inserted in the neuron terminal, either by pressure on the electrode or electrophoretically by pulses of hyperpolarizing current (e.g. Maranto 1982, Zaitseva \& Shuvalova 1988). Schmidt \& Ache (1992) injected biocytin into axons of the antennules of spiny lobsters, which 
allowed the olfactory afferents from chemosensory neurons in aesthetascs to be traced to the olfactory lobe of the lobster brain. Injection of dye tracers requires that the neuron of interest be isolated and be large enough to accommodate the tip of the microelectrode.

The goal of this study was to examine the distribution of aesthetascs and other sensilla on the antennules of several calanoid species as part of a larger study utilizing microvideo techniques to describe small-scale fluid dynamics across the sensory structures of freeswimming copepods. Several studies have investigated the functional morphology and physiology of copepod cuticular sensilla. Strickler \& Bal (1973), Friedman \& Strickler (1975), Barrientos (1980), Gill (1986) and Kurbjeweit \& Buchholz (1991) demonstrated through the use of scanning and transmission electron microscopy that morphologically different setae are innervated by different types of sensory celis. These authors show that aesthetascs and putative mechanoreceptive sensilla on copepod antennules are structurally similar to those described for other crustaceans.

Crustacean aesthetascs are thin-walled cylindrical structures with a stem-like basal part through which the unsheathed ciliary segments of many sensory cells extend to fill the lumen of the sensilla (Ache \& Derby 1985, Tierney et al. 1986, Derby 1989, Hallberg et al. 1992). Aesthetascs are olfactory structures rather than contact chemoreceptors, and there is no evidence that these sensilla contain mechanosensory neurons (Laverack 1988, Derby 1989). In contrast to aesthetascs, mechanoreceptive setae take many morphological forms and are innervated by a few sensory cells. The inner dendritic segments of these neurons are ensheathed by a scolopale matrix and their unsheathed distal segments terminate near the setal base in a microtubule complex (see reviews by Ache 1982, Bush \& Laverack 1982, Laverack 1987, 1988, Hallberg et al. 1992, see also Guse 1980, Felgenhauer \& Abele 1983, Heimann 1984, Tiemey et al. 1986, Grünert \& Ache 1988). Dually functional sensilla which possess both sensory cells types are also common in crustaceans (Altner et al. 1983, Laverack 1987, Derby 1989).

While electron microscopy is to date the only means of resolving smaller cellular components, the methods involved are extremely laborious. The techniques also necessitate the destruction or distortion of the tissue being studied because of the requirement that the sample either be coated with metal for SEM or embedded in plastic and sectioned for TEM. Detailed examination of the ultrastructure of all sensilla on a single antennule by TEM proved to be extremely time consuming and required many specimens, especially for smaller species, while complete comparisons between the antennules of different species were virtually impossible. Consequently, we looked for a way to visualize neuronal projections into a sensillum which was nondestructive and which would allow us to compare the sensory physiology of several species.

The use of membrane-specific fluorescent carbocyanine dyes coupled with laser scanning confocal microscopy (LSCM) allows aesthetascs on the antennules of copepods to be rapidly identified. Carbocyanine dyes are not cytotoxic, and specifically label cell plasma membranes when applied extracellularly. Yoshikami \& Okun (1984) labeled presynaptic nerve terminals in larval Drosophila sp. muscle tissue with $\mathrm{DiOC}_{2}$, a fluorescent short-chain carbocyanine dye, and found that the dye permitted visualization of presynaptic motor nerve terminals at neuromuscular junctions. Honig \& Hume (1986) investigated several long-chain carbocyanine dyes and found that DiIC $_{18}$-(3) or Dil is ideal for neuronal labeling because it is incorporated into the plasma membrane, has no detectable toxic effects and does not spread between neurons when membrane integrity is not disrupted. Axelrod (1979) described the mechanism by which the Dil molecule inserts into the cell membrane. Several authors have utilized Dil and fluorescent microscopy to trace neuronal networks in living and preserved tissue (Godement et al. 1987, Thanos \& Bonhoeffer 1987. Laudel \& Lim 1993). Wallén et al. (1988) utilized DiI and LSCM to create a 3-dimensional reconstruction of neurons in a whole-mount of a lamprey spinal column. We found that DiI intensely labels the copepod aesthetascs when applied externally to the whole animal, and allows neurons at the bases of sensilla and their extensions into setae to be identified.

LSCM provides a means of observing external structures in 3 dimensions while simultaneously visualizing internal neuronal tissue. 1,1'-Dioctadecyl-3,3,3',3'-tetramethylindocarbocyanine perchlorate ['DiI' or $\mathrm{DiIC}_{18}$-(3)] is a long-chain, highly fluorescent dye that brightly labels neurons and their processes (Honig \& Hume 1986). Dil fluoresces brightly when excited with a $546 \mathrm{~nm}$ light source. Since the exoskeleton of the antennule is transparent to the laser, LSCM allows the labeled structures beneath the cuticle to be seen, therefore avoiding destruction of the specimen. Because the laser illuminates only a small section of labeled tissue at a time, both horizontal and vertical resolution are greater than that of conventional fluorescent microscopy. When used in conjunction with TEM, LSCM provides a means of identifying fine-scale structures such as cell somata and dendritic extensions which can then be thin-sectioned to obtain ultrastructural information. The creation of manual reconstructions of nerve fibers from thin sections is no longer necessary, since 3-dimensional reconstructions can be 
made by 'optically sectioning' tissues (Wallén et al 1988). LSCM is a valuable tool which increases our understanding of the functional morphology of sensory structures, and provides a simple means of comparing the sensory structures of different species and of different life-history stages.

\section{MATERIALS AND METHODS}

A stock solution of DiI was made by dissolving $10 \mathrm{mg}$ of crystalline Dil (Molecular Probes, Inc.) in $4 \mathrm{ml}$ of $95 \%$ ethanol. One drop of this solution from a pasteur pipette was added to $4 \mathrm{ml}$ of $95 \%$ ethanol to make a dilute solution of approximately $30 \mu \mathrm{g} \mathrm{ml}^{-1} \mathrm{DiI}$.

Copepods were collected from vertical plankton tows made approximately 20 miles from the shore off the southeastern coast of Georgia, USA. Specimens were fixed for $4 \mathrm{~h}$ in $2 \%$ glutaraldehyde in filtered seawater. The specimens were moved to a 1:1 dilution of seawater and deionized water, then to deionized water. Seawater was not used as a staining solution because salts strongly inhibit dissolution of DiI. From deionized water, the copepods were moved first into $50 \%$ ethanol for $3 \mathrm{~min}$, then to $70 \%$ ethanol. One drop of dilute dye solution was then added for every $\mathrm{ml}$ of $70 \%$ ethanol for 3 min for a final concentration of roughly $1 \mu \mathrm{g} \mathrm{ml}^{-1}$ of DiI. Whole copepods were stained for $10 \mathrm{~min}$. The specimens were then moved to $50 \%$ ethanol for 5 to $10 \mathrm{~s}$, then moved to filtered seawater. All staining solutions were maintained at approximately $5^{\circ} \mathrm{C}$ in an ice bath.

The copepods were decapitated and the heads were mounted in seawater on a glass slide, covered with a cover slip, and observed under a $568 \mathrm{~nm}$ light source using a Biorad MRC600 LSCM, located at the Center for Advanced Ultrastructural Research, University of Georgia. Structures labeled with Dil fluoresce bright orange when viewed with this system. A standard fluorescent microscope with appropriate filters can be used to rapidly identify the strongly labeled setae on the antennules, although fine structure within the antennule cannot be resolved due to background fluorescence of tissue above and below the structures of interest.

We followed the procedure described above with the distal segments of the lateral antennular filament of a crayfish (Procambarus sp.). The physiology and innervation of crayfish antennular sensilla have been well described by tracer and ultrastructural studies (Tierney et al. 1986, Mellon \& Munger 1990), and therefore, the Dil labeling of crayfish aesthetascs provides a good model for comparison with the patterns of Dil labeling of neurons which innervate copepod sensilla.

LSCM utilizes a digital imaging fluorescence microscope equipped with an $\mathrm{Ar} / \mathrm{Kr}$ laser which can be focused on an extremely narrow focal plane. Structures above and below the focal plane therefore do not mask the structures being imaged. Images collected in a single focal plane are stored digitally, and the microscope stage is then moved up or down to the next plane of interest. Images can be collected with a vertical resolution of $0.2 \mu \mathrm{m}$ and can be examined separately or 'stacked' to create a compiled image of the specimen The image can be animated and viewed from all sides by utilizing image-processing software. We used a software package called 'VoxelView' which was developed by Vital Images, Inc, and which is available for Macintosh computers and for Silicon Graphics workstations. By creating animated 3-dimensional views of the data sets, we were able to rotate and visualize an entire antennule, its setae, and its internal structures in 3 dimensions. For a comprehensive description of confocal microscopy and image-processing techniques, refer to Caldwell et al. (1992).

We used recently preserved specimens in this study, even though Dil is not toxic to neuronal tissue (Honig \& Hume 1986). Copepod specimens which had been preserved in fixative for more than a few days stained poorly and rapid bleaching of the dye occurred when the tissue was illuminated with the laser. Internal structures were not stained specifically, while some spots on the cuticle glowed brightly. Photobleaching also occurred when specimens were observed for a long time at higher magnifications and when a hydrocarbon-based mounting medium was used as a cover slip sealant. Allowing the specimens to remain in $50 \%$ ethanol for more than a few seconds resulted in amorphous staining of neuronal structures.

Photographs obtained from LSCM images lose resolution when transferred to film because analog confocal signals must first be transformed to digital format and stored on disk. They are then displayed as an image on a monitor screen for analysis and must be captured by 'frame-grabber' hardware before being transferred to film or to a video print. Because the original image is in a digital format, the resolution of a photograph taken of a screen image is limited by the resolution of the frame grabber.

Copepods examined in this study include adult female Centropages velificatus, Calanopia elliptica, Eucalanus pileatus, Temora stylifera and Labidocera aestiva.

\section{RESULTS}

\section{General results}

Fig. 1 shows confocal images of the antennules of female Labidocera aestiva, Eucalanus pileatus, Centropages velificatus and Calanopia elliptica. Differen- 

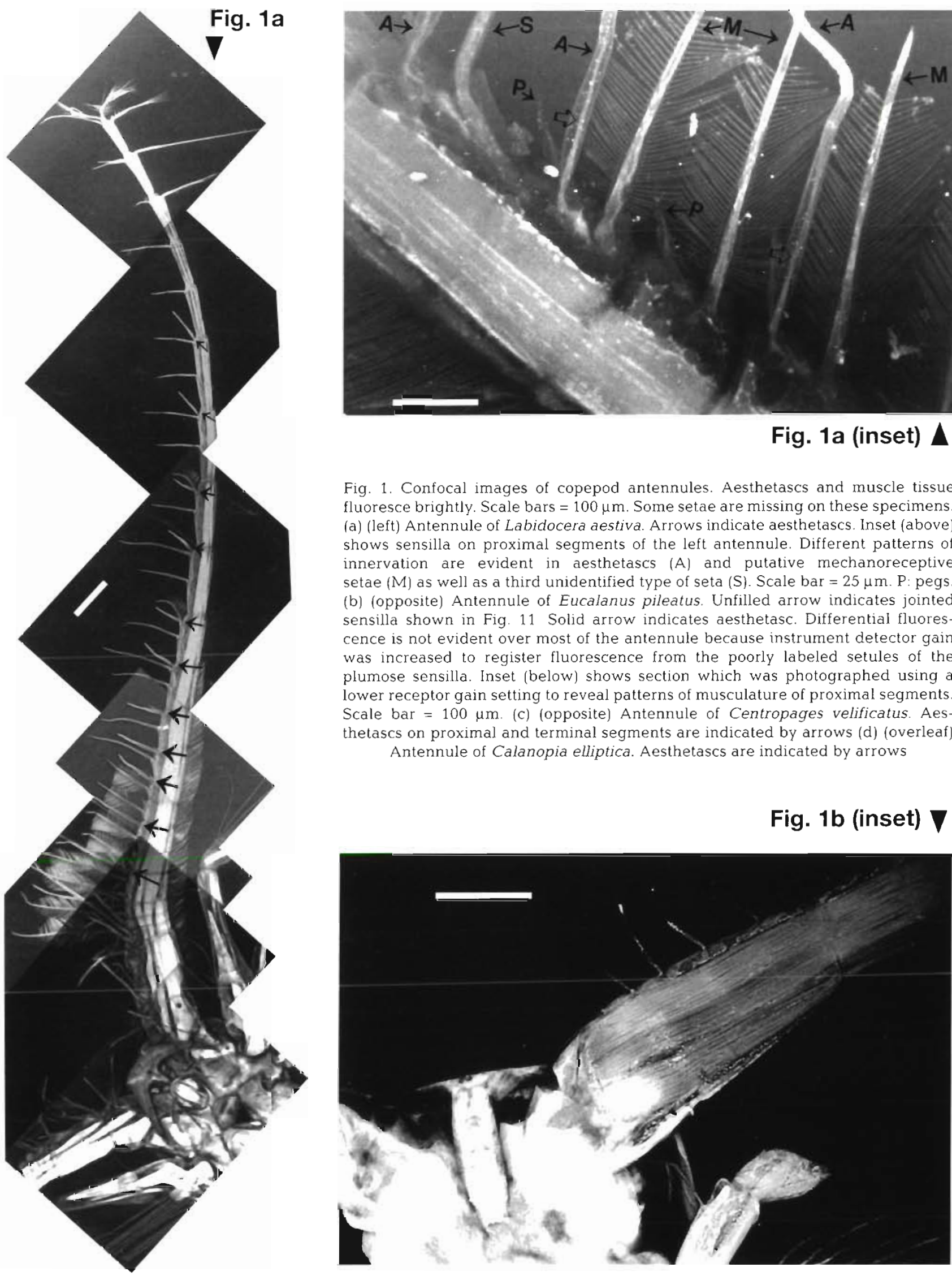

Fig. 1a (inset) $\Delta$

Fig. 1. Confocal images of copepod antennules. Aesthetascs and muscle tissue fluoresce brightly. Scale bars $=100 \mu \mathrm{m}$. Some setae are missing on these specimens. (a) (left) Antennule of Labidocera aestiva. Arrows indicate aesthetascs. Inset (above) shows sensilla on proximal segments of the left antennule. Different patterns of innervation are evident in aesthetascs (A) and putative mechanoreceptive setae (M) as well as a third unidentified type of seta (S). Scale bar $=25 \mu \mathrm{m}$. P: pegs. (b) (opposite) Antennule of Eucalanus pileatus. Unfilled arrow indicates jointed sensilla shown in Fig. 11 Solid arrow indicates aesthetasc. Differential fluorescence is not evident over most of the antennule because instrument detector gain was increased to register fluorescence from the poorly labeled setules of the plumose sensilla. Inset (below) shows section which was photographed using a lower receptor gain setting to reveal patterns of musculature of proximal segments. Scale bar $=100 \mu \mathrm{m}$. (c) (opposite) Antennule of Centropages velificatus. Aesthetascs on proximal and terminal segments are indicated by arrows (d) (overleaf) Antennule of Calanopia elliptica. Aesthetascs are indicated by arrows

Fig. 1b (inset) $\nabla$

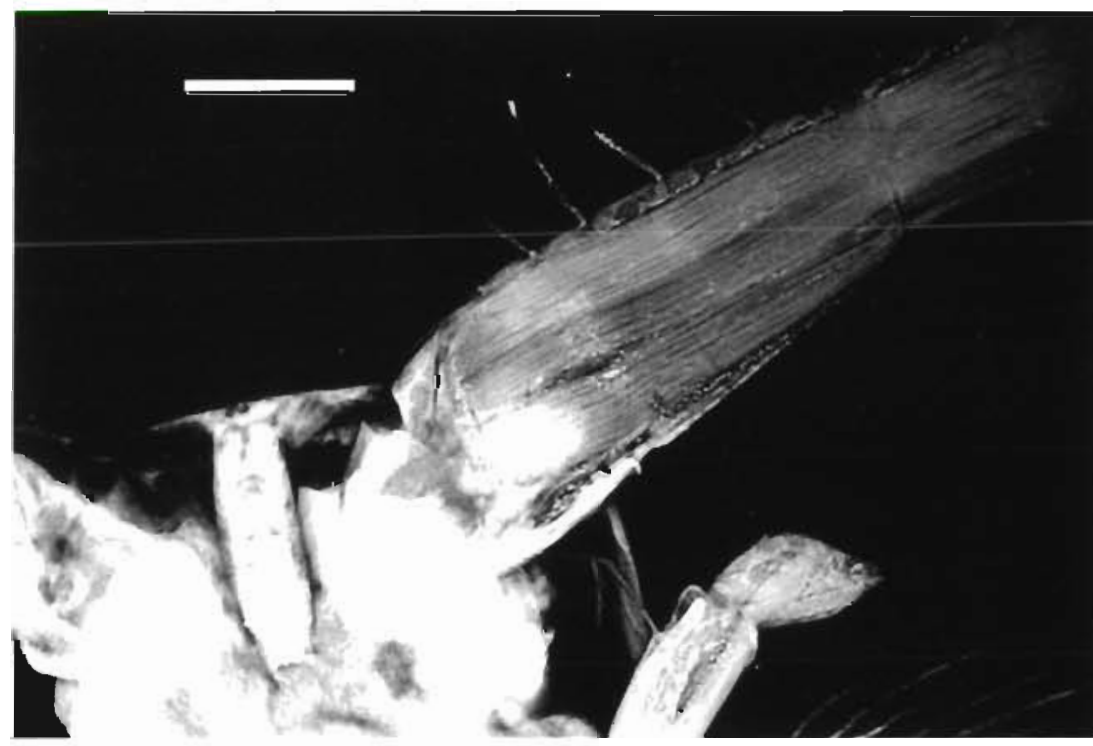


Fig. 1b $\nabla$

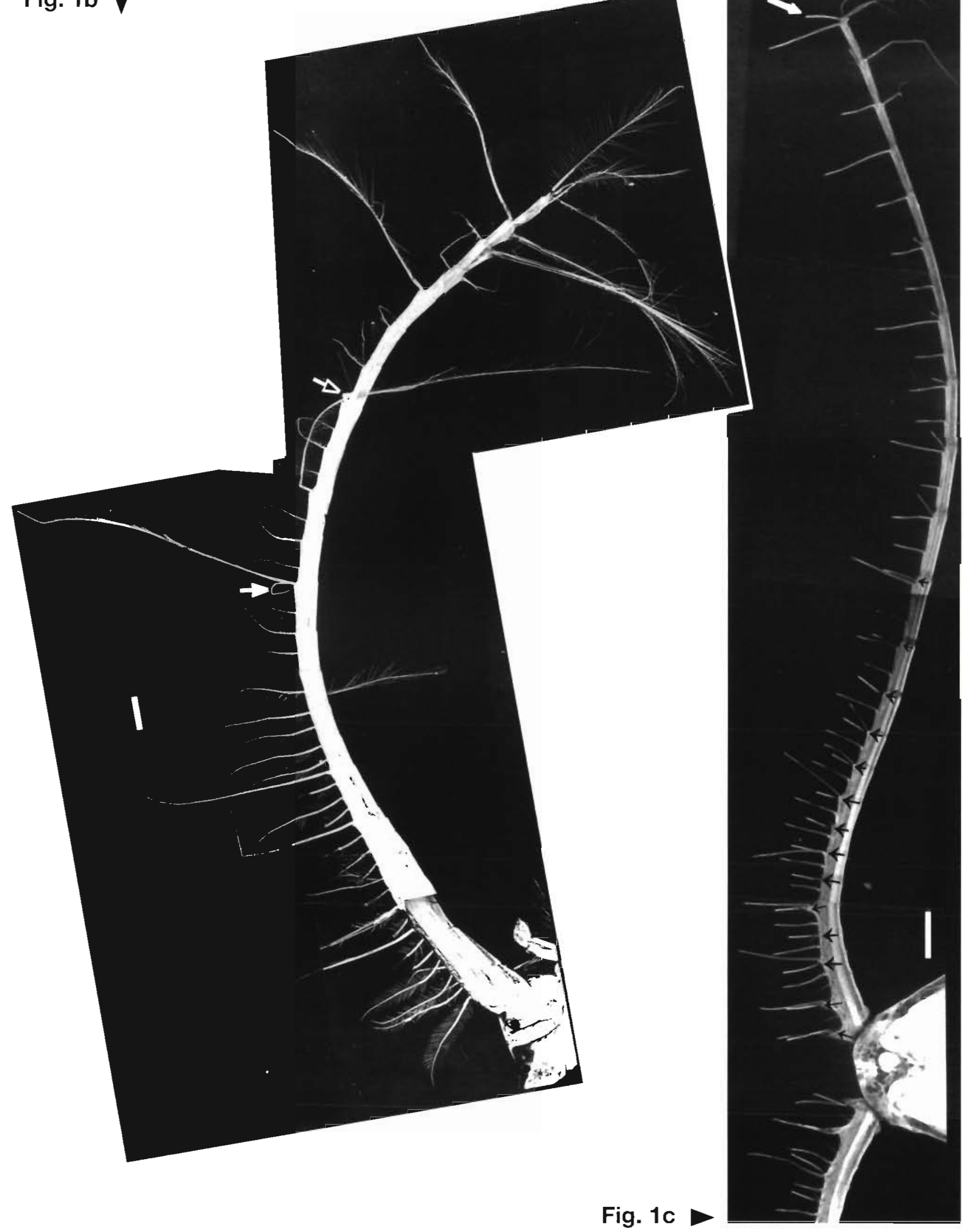




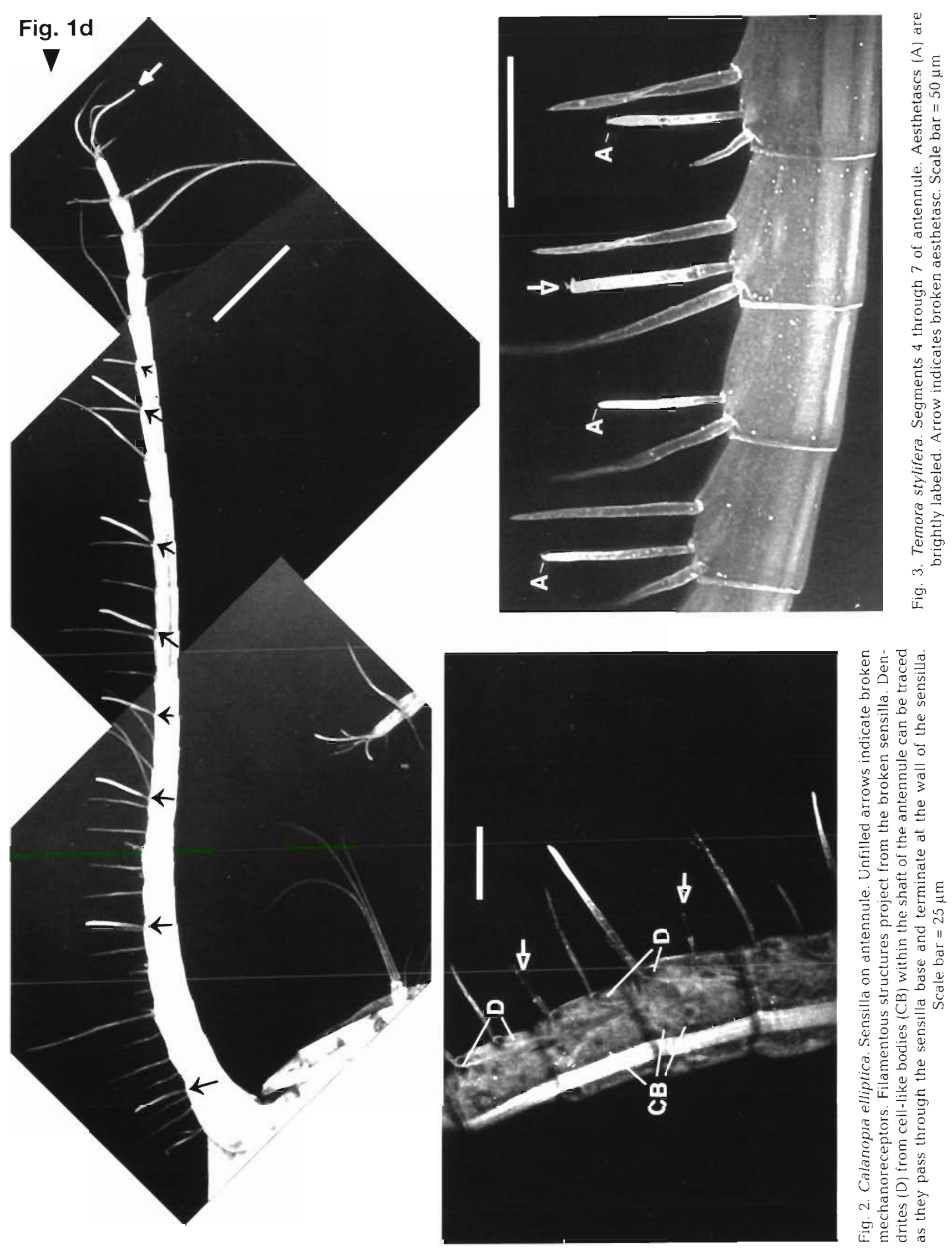


tial labeling by Dil indicates that setae differ in their patterns of innervation. Smooth (bearing no setules) bulbous sensilla fluoresce brightly for their entire length, while other sensilla show variable degrees of fluorescent label. The smooth pointed sensilla of $C$. velificatus and $C$. elliptica fluoresce no more brightly than surrounding tissue (Fig $1 c \& d$ ), while long plumose sensilla of $E$, pileatus have strands of labeled material extending their entire length (Fig. 1b; see also Fig. 8a). The distal portions of smooth pointed and feathered setae on the antennule of $L$. aestiva fluoresce similarly to neighboring smooth bulbous sensilla (Fig. 1a inset).

To determine if cuticle impermeability restricted DiI entry into the unlabeled sensilla, broken smooth setae were compared with broken aesthetascs. Broken smooth setae show no evidence of fluorescent label, even though in some cases filamentous structures can be seen projecting from the broken shaft (Fig. 2). In contrast to broken smooth setae, broken aesthetascs fluaresce brightly (Fig. 3)

The patterns of innervation of crayfish aesthetascs are revealed when these structures are labeled with Dil and examined using LSCM (Fig. 4). Tierney et al. (1986) and Mellon \& Munger (1990) describe the innervation of crayfish aesthetascs. The inner dendritic segments of the aesthetasc sensory neurons leave the sensory ganglion and form bundles which are enclosed by sheath cells. The bundles pass through a receptor lymph cavity, where the dendrites branch into ciliary segments and enter the base of the sensilla. Still supported loosely by sheath cells, the ciliary segments extend into the lumen of the aesthetasc. Dendritic bundles can be seen in Fig. 4 as they leave the sensory ganglion, pass through a lumen and enter the aesthetasc sensilla.

\section{Aesthetasc sensilla}

The setae identified as aesthetascs in this study have characteristics consistent with those described in ultrastructural studies of other crustacean taxa. The definitive characteristics of an aesthetasc, as described by Hallberg et al. (1992), include a tubelike shape with a thin cuticle and innervation by the distal ciliary segments of sensory cells which are surrounded basally by enveloping cells. The ciliary segments leave the sheath of the enveloping cells and enter and fill the sensilla. Copepod aesthetascs are bulbous in shape, with a constricted 'neck' at the base, and are innervated by the ciliary segments of as many as 30 sensory cells which fill the lumen of the sensilla (Barrientos 1980, Gill 1986, Kurbjeweit \& Buchholz 1991). DiI-labeled aesthetasc sensilla have a constricted 'stem', and labeled material is evident at the point of the constriction (Fig. 5). The constriction marks the region where ciliary segments arise from the distal dendrites of the sensory neuron (Kurbjeweit \& Buchholz 1991). The entire sensilla is intensely labeled. The bright fluorescence indicates that extensive cell membrane is present throughout the structure, a feature which is indicative of chemosensory function (Laverack 1988).

The aesthetascs of Labidocera aestiva differ from those of the other species examined in that the dendritic bundle remains constricted until it reaches the level where the setules on neighboring setae end (Figs. 1a \& 6a). At this point, the tip of the aesthetasc becomes strongly labeled, indicating that the surface area of cell membrane has increased, possibly due to division of ciliary dendritic extensions. There appears to be a cluster of dendrites proximal to the base of the sensilla (Fig. $6 a, b$ ). These dendrites merge just below the cuticle to form the dendritic bundle. 'Pegs' or shortened seta are also present on the proximal segments (Figs. 1a \& 6a). Although Dil labelling reveals that neuronal tissue extends into these setae, their function is unknown. Kurbjeweit \& Buchholz (1991) suggest that the pegs are chemosensory in function. LSCM images reveal that these structures lack the constriction of the dendritic bundle which is characteristic of aesthetascs (Fig. 6a)

\section{Putative mechanoreceptive sensilla}

Because mechanoreceptors are so varied in their structure and dually functional setae are common on the appendages of crustaceans, it is impossible to be sure of the functional mode of these setae without ultrastructural studies of the dendritic extensions of mechanoreceptive neurons into the setal base and physiological studies showing responses of these neurons to discrete mechanical stimuli. Therefore, for the purposes of this study, unlabeled setae showing distinct basal innervation will be considered as putative mechanoreceptive sensilla. These setae lack a bulbous shape and a constricted neck, and the setal lumen is not filled with intensely labeled neuronal membrane. They are either smooth or plumose and show variable patterns of Dil labeling. Tubular bodies are visible at the bases of many of the sensilla (Figs. 6b \& 7). Tubular bodies are formed by the accumulation of microtubules at the distal dendritic segment of the sensory neuron and are indicative of mechanoreceptive function as well as being the likely site of signal transduction (McIver 1975, French 1988). 

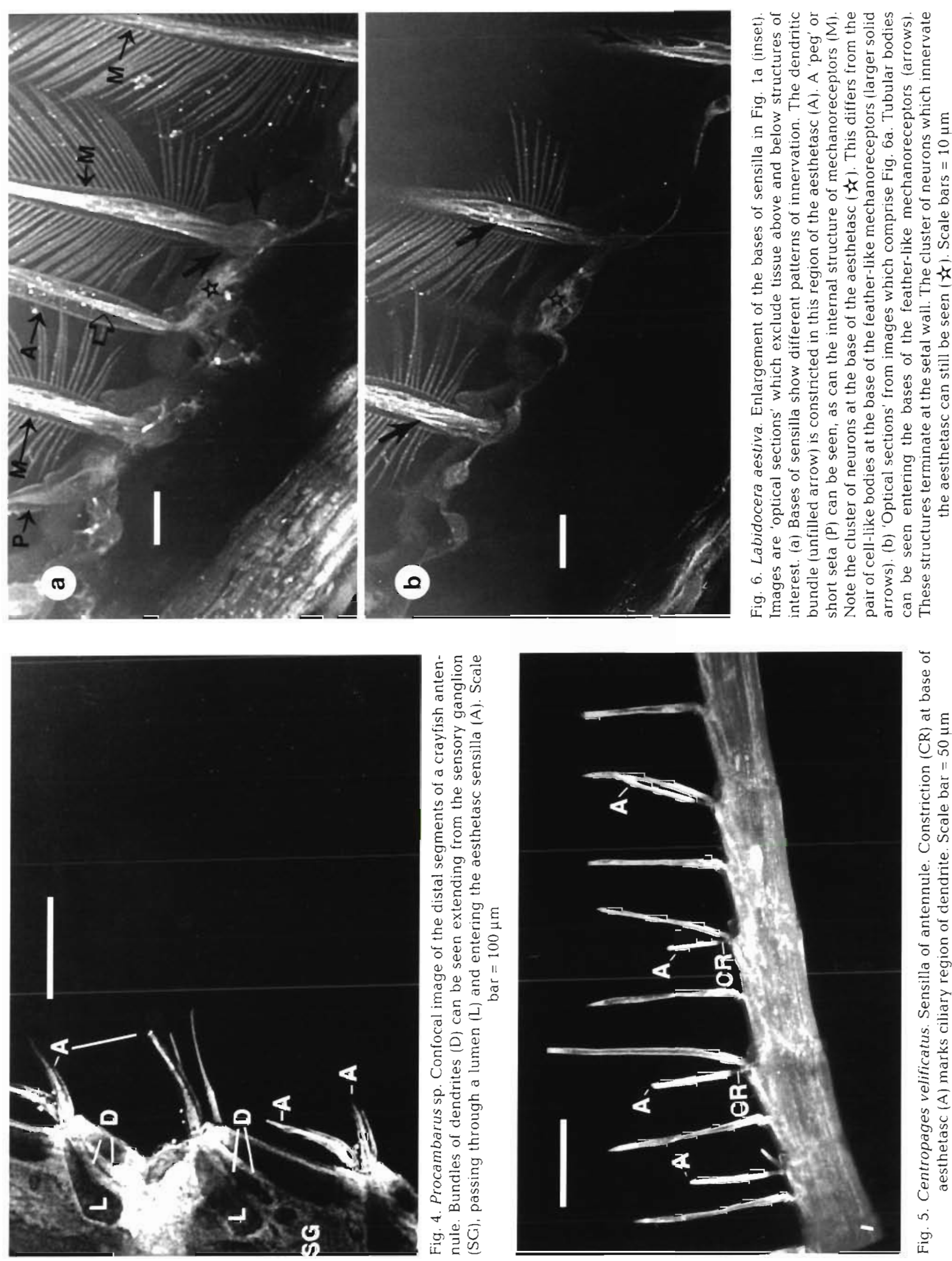

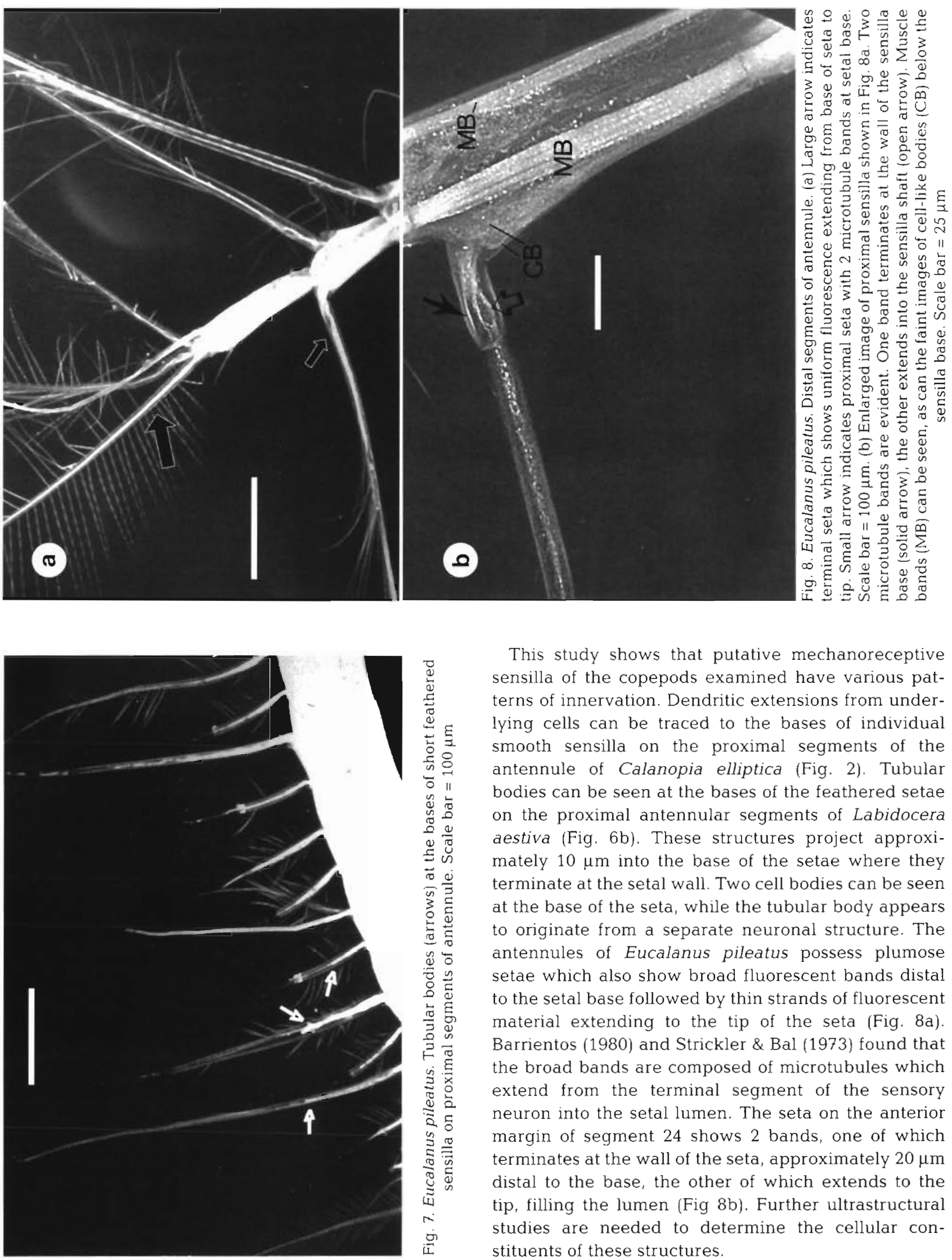

This study shows that putative mechanoreceptive sensilla of the copepods examined have various patterns of innervation. Dendritic extensions from underlying cells can be traced to the bases of individual smooth sensilla on the proximal segments of the antennule of Calanopia elliptica (Fig. 2). Tubular bodies can be seen at the bases of the feathered setae on the proximal antennular segments of Labidocera aestiva (Fig. 6b). These structures project approximately $10 \mu \mathrm{m}$ into the base of the setae where they terminate at the setal wall. Two cell bodies can be seen at the base of the seta, while the tubular body appears to originate from a separate neuronal structure. The antennules of Eucalanus pileatus possess plumose setae which also show broad fluorescent bands distal to the setal base followed by thin strands of fluorescent material extending to the tip of the seta (Fig. 8a) Barrientos (1980) and Strickler \& Bal (1973) found that the broad bands are composed of microtubules which extend from the terminal segment of the sensory neuron into the setal lumen. The seta on the anterior margin of segment 24 shows 2 bands, one of which terminates at the wall of the seta, approximately $20 \mu \mathrm{m}$ distal to the base, the other of which extends to the tip, filling the lumen (Fig 8b). Further ultrastructural studies are needed to determine the cellular constituents of these structures. 

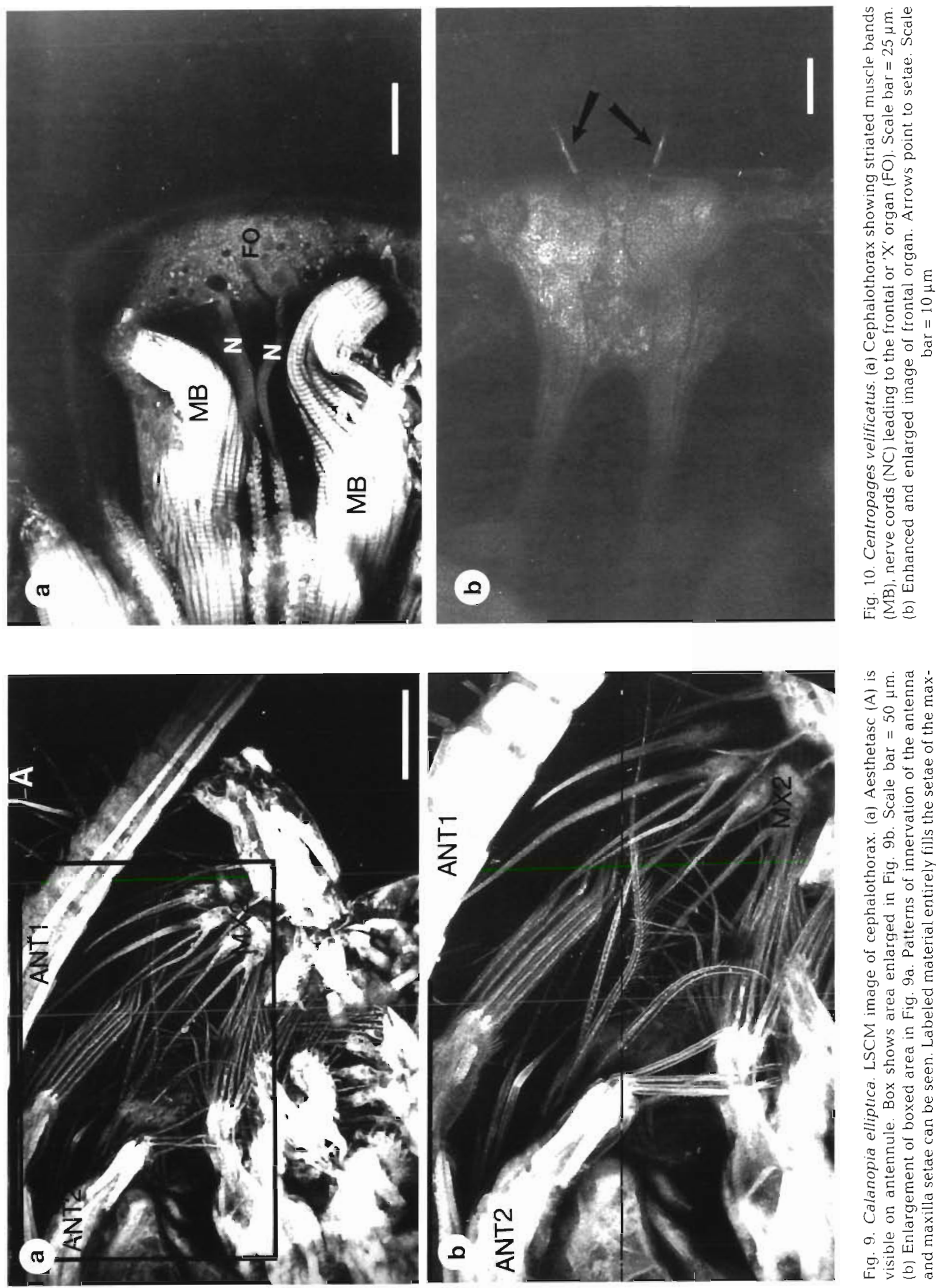

$\leadsto \dot{2} \dot{x}$ उ志㤩

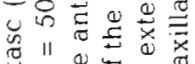

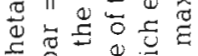

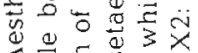
$\varangle \bar{U} \cong$ 过

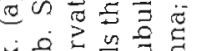

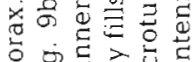

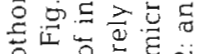

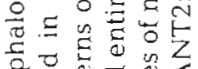

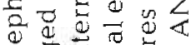
0 西 ठㅁ

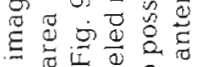
$\sum_{3} \infty 000$

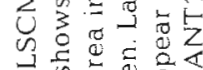
的需

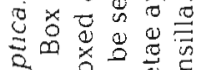

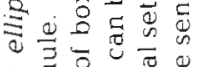

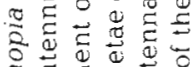

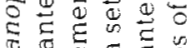

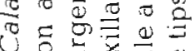

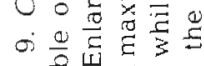

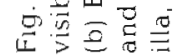




\section{Sensilla on the mouthparts}

The mouthparts of calanoid copepods are believed to function as contact chemosensors, and may also be involved in the remote sensing of chemical cues in the feeding current (Friedman \& Strickler 1975, Price \& Paffenhöfer 1985) Friedman \& Strickler (1975) found that the sensilla on all of the mouthparts of Diaptomus sp. possess chemoreceptor neurons, while Price \& Paffenhöfer (1985) observed that Eucalanus hyainus females change the orientation and frequency of mouthpart movements when large diatoms are entrained in the feeding current. LSCM images of the mouthparts of Calanopia elliptica (Fig. 9a) show the innervation of the setae of the antennae (second antennae) and the maxillae (second maxillae). These sensilla have internal cores of labeled material. The setae of the antennae have thin labeled cores surrounded by a thick cuticle while the setae of the maxilla are strongly labeled in their entirety (Fig. 9b).

\section{Other structures}

Other structures which can be visualized using this technique include muscle bands and nerve tracts. In Fig. $10 a, b$, the nerve tracts which run from the anterior portion of the brain to the frontal or ' $\mathrm{X}$ ' organ can be seen. The frontal organs are believed to be chemosensory in function (Elofsson 1971). Although they lack the characteristic 'club-like' shape of other copepod aesthetascs, the setae associated with them are strongly labeled by DiI.

\section{DISCUSSION}

\section{Utility of laser scanning confocal microscopy}

LCSM gains its advantage over conventional light or fluorescent microscopy because the images are collected by focusing the laser only on a small area of the plane of interest, thereby eliminating any interference from structures surrounding this area which would obscure the image. The images are stored in a digital format and can therefore be manipulated through the use of image-analysis software. 'Optical crosssections' of the specimen can be obtained by recalling individual images from data sets composing whole specimen images. Fig. 11a shows the composite of Images 1 through 20 of the posteriorly projecting seta on the antennule of Eucalanus pileatus. This seta is 'jointed' and Images 11 through 20 show that it extends under the ventral surface of the antennule (Fig. 11b). By examining only Image 17 of the 20 images that make up the composite image, a crosssection of the seta can be obtained which shows a cylindrical core of labeled material (Fig. 11c).

LSCM also provides a means of visualizing the spatial relationship of morphological features while avoiding destruction or deformation of the tissue. Composite images can be animated and rotated so that structures can be seen in 3 dimensions. For example, Labidocera aestiva and Eucalanus pileatus both have feather-like setae which are closely packed on the proximal segments of the antennule (Fig. 1a, b). When the images are animated and rotated about the axis of the antennule, it can be seen that the feathered sensilla fall in a single plane and that their setules overlap each other. The longer setae, which have been identified as putative mechanoreceptors by ultrastructural studies of $E$. pileatus antennules (Barrientos 1980), are oriented in a more dorsal plane.

\section{Functional morphology of sensory structures}

If copepod feeding currents provide a vehicle for remotely detecting chemical cues released by phytoplankton, then the orientation of aesthetascs relative to the feeding current should affect the chemosensory ability of the copepod. For example, Eucalanus pileatus, Centropages velificatus, Labidocera aestiva and Temora stylifera are efficient herbivores which generate strong feeding currents (Paffenhöfer et al. 1982 Price \& Paffenhöfer 1986, Marcus 1988, Tiselius \& Jonsson 1990, M. H. Bundy pers. obs.). The feeding currents of $C$. velificatus, $L$. aestiva and $T$. stylifera differ from that of $E$. pileatus because the streamlines of their feeding currents can impact the copepods anterioventrally, as the copepods swim with their bodies oriented vertically. In the case of $C$. velificatus, Bundy \& Paffenhöfer (1992) found that the feeding current velocity crossing the sensilla on the most proximal segments can be as high as $10 \mathrm{~mm} \mathrm{~s}^{-1}$. In contrast, the feeding current isolines of $E$. pileatus form a cone, the apex of which is the mouth of the copepod and the base of which extends ventrally as the copepod moves slowly, dorsal side down (Paffenhöfer \& Lewis 1990). Very little of this feeding current impinges upon the antennule. Three-dimensional LSCM images reveal that the aesthetascs on the antennules of $C$. velificatus, $L$. aestiva and $T$. stylifera project ventrally, away from the row of smooth and feathered unlabeled setae and toward the flow of the feeding current, while the antennule of $E$. pileatus appears to possess only a single aesthetasc.

LSCM images of putative mechanoreceptive sensilla may provide insights into the mechanics of signal transduction in these setae, because the length of the 


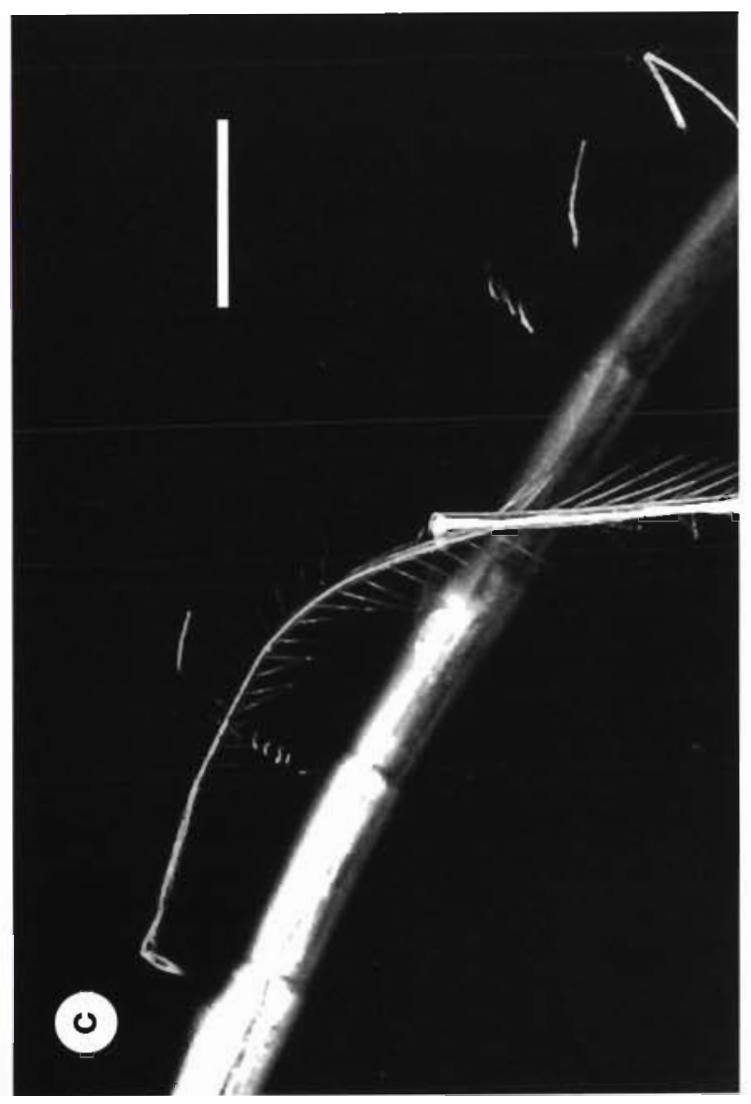

seta and the points at which tubular bodies attach to the wall of the setal lumen may affect setal mobility and the directional sensitivity of the mechanoreceptive neurons (Tautz 1979, 1990, Gnatzy \& Tautz 1980). Figs. 2, 6, $7 \& 8$ show the antennules of Calanopia elliptica, Labidocera aestiva and Eucalanus pileatus. Dendritic extensions of sensory cells and their attachment point in the setal lumen can be seen. The ability to visualize the patterns of innervation of the sensilla while simultaneously observing the orientation of all the setae on the antennule may allow us to relate the physical coupling of hydrodynamic signals to the physiology of the structures involved in signal transduction.

Wainwright (1991) addresses the problem of relating the functional morphology of an organism to the patterns with which it utilizes resources. Following the methodology proposed by Wainwright, the role of the antennule in remotely sensing chemical cues in the feeding current can be assessed by first determining the physiological potential of the antennule to perceive signals. In this case, the question asked is: does the feeding current contact the sensory array of the antennule, and is the sensory array physically capable of receiving the signals?. The hypothesis of this investigation is that the distribution and number of aesthetascs on the antennules of herbivorous copepods
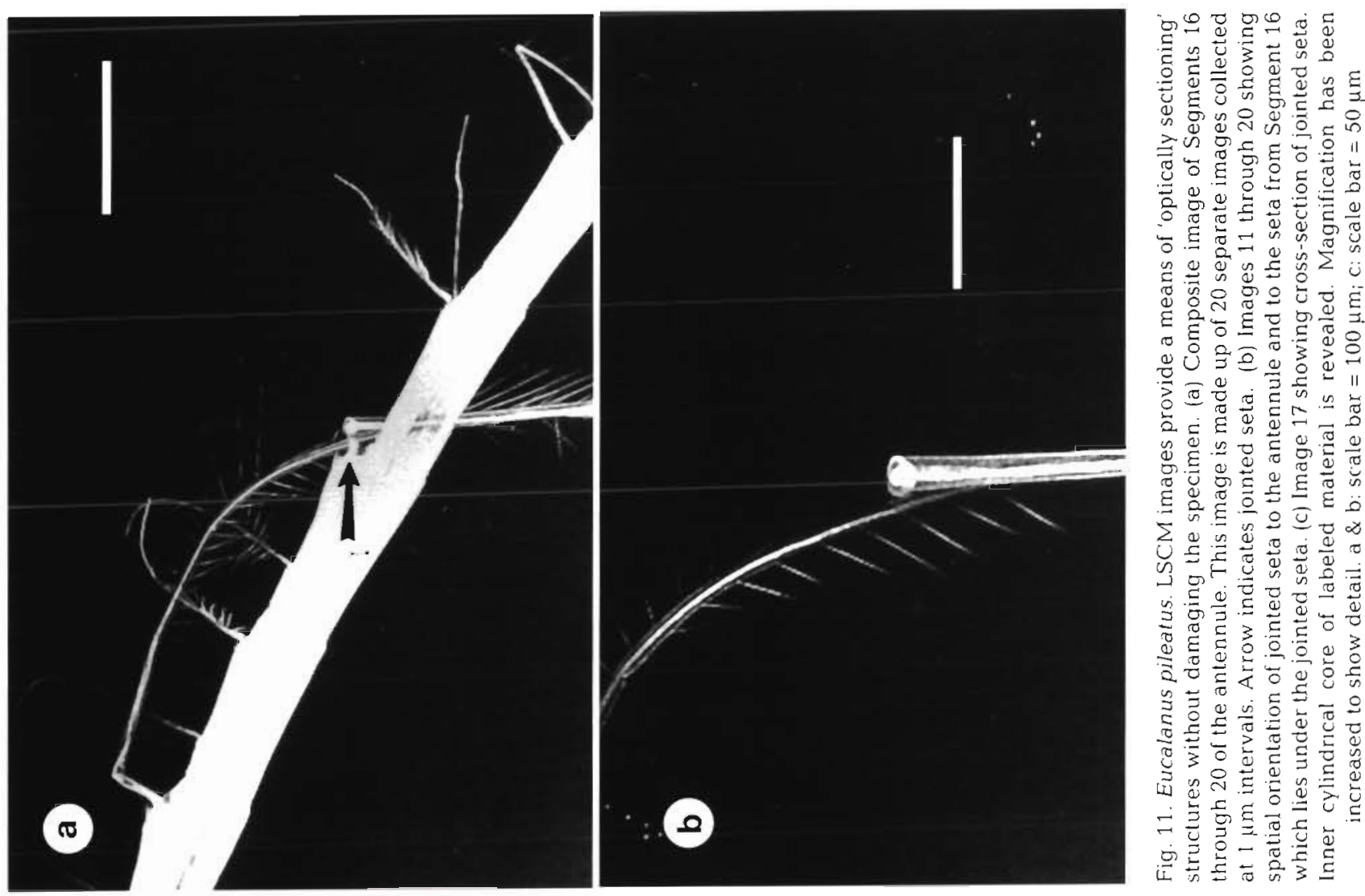
are related to the extent that the feeding current impacts these sensilla. Herbivorous species which create a pronounced feeding current involving the antennule are expected to have many aesthetascs exposed to the flow. Herbivorous or omnivorous species whose antennules are not exposed to the feeding current, or carnivorous species which rely mainly on mechanoreception to detect prey, are expected to have few if any aesthetascs on the antennules. A factor which complicates this scenario is that aesthetascs may also function in the remote sensing of predators (Folt $\&$ Goldman 1981), or in the detection of diffuse chemical stimuli.

Work in progress focuses on comparing the streamlines of the feeding currents of free-swimming Centropages velificatus, $C$. hamatus and Paracalanus aculeatus and relating the results to the type and distribution of sensilla on the antennules and the mouthparts of each species. LSCM provides a nondestructive means of identifying aesthetascs and other neuronal structures while maintaining the integrity of their spatial relationship to other tissues. Although the images provided by the LSCM do not allow resolution of cellular ultrastructure, they do reveal fine-scale patterns of innervation and musculature. The methods employed in specimen preparation are simple and identification of aesthetascs can be made using a standard fluorescent microscope. The use of this tool provides an efficient means of rapidly and easily comparing the sensory structures of many species. When coupled with studies of feeding behavior and predator-prey interactions, visualization of sensory organ structure will provide valuable information regarding the links between physiology, behavior and ecology.

Acknowledgements. We thank Dr Mark A. Farmer for his generosity and assistance with the LSCM and for critically reading the manuscript. Dr C. D. Derby provided constructive comments which greatly improved the manuscript and we thank him for his time. This research was supported by the Skidaway Institute of Oceanography and the National Science Foundation (grant OCE 90-00144) to G.-A.P. We thank A. Boyette for help with the figures.

\section{LITERATURE CITED}

Ache, B. W. (1982). Chemoreception and thermoreception. In: Sandeman, D. C. (ed.) The biology of Crustacea, Vol. 3, Neurobiology: structure and function. Academic Press, New York, p. 369-398

Ache, B. W., Derby, C. D. (1985). Functional organization of olfaction in crustaceans. Trends Neurosci. 8: $356-360$

Altner, I., Hatt, H., Altner, H. (1983). Structural properties of bimodal chemo- and mechanosensitive setae on the pereiopod chelae of the crayfish, Austropotamobius torrentium. Cell Tissue Res. 244: 537-547

Atema, J. (1985). Chemoreception in the sea: adaptations of chemoreceptors and behaviour to aquatic stimulus conditions. Symp. Soc. exp. Biol. 39: 387-423
Axelrod, D. (1979). Carbocyanine dye orientation in red blood cell membrane studied by microscopic fluorescence polarization. Biophys. J. 26: $557-574$

Barrientos, Y (1980). Ultrastucture of sensory units of the first antennae of calanoid copepods. M.Sc. thesis, Univ. of Ottawa

Bundy, M. H., Paffenhofer, G.-A. (1992). Behavior, flow field geometry, and sensory morphology as determinants of copepod perceptive volume. Spring Meeting, Am. Soc. Limnol. Oceanogr, Santa Fe (abstract)

Bush, B. M. H., Laverack, M. S. (1982). Mechanoreception. In: Sandeman, D. C. (ed.) The biology of Crustacea, Vol. 3 , Neurobiology: structure and function. Academic Press, New York, p. 399-468

Buskey, E. J. (1984). Swimming pattern as an indicator of the roles of copepod sensory systems in the recognition of food. Mar. Biol. 79: 165-175

Caldwell, D. G., Korber, D. R., Lawrence, J. R. (1992). Confocal laser microscopy and digital image analysis in microbial ecology. Advances in microbial ecology, Vol. 12. Plenum Press, New York, p. 1-67

Derby, C. D. (1989). Physiology of sensory neurons in morphologically identified cuticular sensilla of crustaceans. In: Thistle, A. B. (ed.) Functional morphology of feeding and grooming in crustaceans. A. A. Balkema, Rotterdam, p. $27-47$

Elofsson, R. (1971). The ultrastructure of a chemoreceptor in the head of copepod crustaceans. Acta zool. Stockholm 52: $299-315$

Felgenhauer, B. E., Abele, L. G. (1983). Ultrastructure and functional morphology of feeding and associated appendages in the tropical freshwater shrimp Atya innocous (Herbst) with notes on its ecology. J. crust. Biol. 3: 336-363

Folt, C., Goldman, C. R. (1981). Allelopathy between zooplankton: a mechanism for interference. Science 213: 1133-1135

French, A. S. (1988). Transduction mechanisms of mechanosensilla. A. Rev. Ent. 33: 39-58

Friedman, M. M., Strickler, J. R. (1975). Chemoreceptors and feeding in calanoid copepods (Arthropoda: Crustacea). Proc. natl Acad. Sci. U.S.A. 72: 4185-4188

Gill, C. W. (1986). Suspected mechano- and chemosensory structures of Temora longicornis. Mar. Biol 93: 449-456

Gill, C. W., Crisp, D. J. (1985). Sensitivity of intact and antennule-amputated copepods to water disturbance. Mar. Ecol. Prog. Ser. 21: 221-227

Gnatzy, W., Tautz, J. (1980). Ultrastructure and mechanical properties of an insect mechanoreceptor: stimulustransmitting structures and sensory apparatus of the cercal filiform hairs of Gryllus. Cell Tissue Res. 213: $441-463$

Godement, P., Vanselow, J., Thanos, S., Bonhoeffer, F. (1987). A study in developing visual systems with a new method of staining neurons and their processes in fixed tissue. Development 101.697-713

Grünert, U., Ache, B. W. (1988). Ultrastructure of the aesthetasc (olfactory) sensilla of the spiny lobster Panulirus argus. Cell Tissue Res. 251. 95-103

Guse, G.-W. (1980). Development of antennal sensilla during moulting in Neomysis integer (Leach) (Crustacea, Mysidacea). Protoplasma 105: 53-67

Hallberg, E., Johansson, K. U. I., Elofsson, R. (1992). The aesthetasc concept: structural variations of putative olfactory receptor cell complexes in Crustacea. Microsc. Res. Tech. 22: 325-335

Heimann, P. (1984). Fine structure and molting of aesthetasc sense organs on the antennules of the isopod, Asellus aquaticus (Crustacea). Cell Tissue Res. 235: 117-128 
Honig, M. G., Hume, R. I. (1986). Fluorescent carbocyanine dyes allow living neurons of ldentified origin to be studied in long term cultures. J. Cell Biol. 103: $171-187$

Huntley, M., Sykes, P., Rohan, S., Marin, V. (1986). Chemically mediated rejection of dinoflagellate prey by the copepod Calanus pacificus and Paracalanus parvus: mechanism, occurrence and significance. Mar. Ecol. Prog. Ser. 28: 105-120

Katona, S. K. (1973). Evidence for sex pheromones in planktonic copepods. Limnol. Oceanogr. 18: 574-583

Kurbjeweit, F., Buchholz, C. (1991). Structures and suspected functions of antennular sensilla and pores of three Arctic copepods (Calanus glacialis, Metridia longa, Paraeucheata norvegica). Meeresforsch. 33: 168-182

Laudel, T P., Lim, T. (1993). Development of the dorsal root ganglion in a teleost, Oreochromis mossambicus (Peters). J. Comp. Neurol. 327: 141-150

Laverack, M. S. (1987). The nervous system of Crustacea with special reference to the organization of the sensory system. In: Ali, M. A. (ed.) Nervous systems in invertebrates. Plenum Press, New York, p. 323-351

Laverack, M. S. (1988). The diversity of chemoreceptors. In: Tavolga, W. N. (ed.) Sensory biology of aquatic organisms. Springer-Verlag, New York, p. 287-312

Maranto, A. R. (1982). Neuronal mapping: a photooxidation reaction makes Lucifer yellow useful for electron microscopy. Science 217: 953-955

Marcus, N. H. (1988). Photoperiod conditions, food patchiness, and fecundity. Bull. mar. Sci. 43: 641-649

Mclver, S. B. (1975). Structure of cuticular mechanoreceptors of arthropods. A. Rev. Ent. 20: 381-397

Mellon, D., Munger, S. D. (1990). Nontopographic projection of olfactory sensory neurons in the crayfish brain. J. comp. Neurol. 296: 253-262

Paffenhöfer, G.-A., Lewis, K. D. (1990). Perceptive performance and feeding behavior of calanoid copepods. J Plankton Res, 12: 933-946

Paffenhöfer, G.-A., Strickler, J. R., Alcaraz, M. (1982). Suspension feeding by herbivorous planktonic copepods: a cinematographic study. Mar. Biol. 67: 193-199

Poulet, S. A., Marsot, P. (1980). Chemosensory feeding and food-gathering by omnivorous marine copepods. In: Kerfoot, W. C. (ed.) Evolution and ecology of zooplankton communities. University Press of New England, Hanover, p. $198-218$

Poulet, S. A., Ouellet, G. (1982). The role of amino acids in the chemosensory swarming and feeding behavior of marine copepods. J. Plankton Res. 4: 341-361

Price, H. J., Paffenhöfer, G.-A. (1985). Perception of lood availability by calanoid copepods. Arch. Hydrobiol Beih Ergeb. Limnol. $21 \quad 115-124$

This article was presented by B. \& E. Sherr, Corvalls, Oregon, USA
Price, H. J., Paffenhöfer, G.-A. (1986). Effects of concentration on the feeding of a marine copepod in algal monocultures and mixtures. J. Plankton Res. 8: 119-128

Schmidt, M., Ache, B. W. (1992). Antennular projections to the midbrain of the spiny lobster. 2 . Sensory innervation of the olfactory lobe. J. comp. Neurol. 318: 291-303

Strickler, J. R., Bal, A. K. (1973). Setae of the first antennae of the copepod Cyclops scutifer (Sars): their structure and importance. Proc. natl Acad. Sci. U.S.A. 70: 2656-2659

Strickler, J. R., Twombly, S. (1975). Reynolds number, diapause, and predatory copepods, Verh. int. Verein. Limnol. 19: $2943-2950$

Tautz, J. (1979). Reception of particle oscillation in a medium - an unorthodox sensory capacity. Naturwissenschaften 65: $452-461$

Tautz, J. (1990). Can the directional sensitivity of single mechanosensory neurons in arthropods tell the animal anything about stimulus direction? In: Gribakin, F. G., Wiese, K., Popov, A. V. (eds.) Sensory systems and communication in arthropods. Birkbauser Verlag, Basel, p. $359-363$

Thanos, S., Bonhoeffer, F. (1987). Axonal arborization in the developing chick retinotectal system. J. comp. Neurol. $261: 155-164$

Tierney, A. J., Thompson, C. S., Dunharn, D. W. (1986). Fine structure of aesthetasc chemoreceptors in the crayfish Orconectes propinquus. Can. J. Zool. 64: 392-399

Tiselius, P., Jonsson, P. (1990). Foraging behavior of six calanoid copepods: observations and hydrodynamic analysis. Mar. Ecol. Prog. Ser. 66: 23-33

Uchima, M., Murano, M. (1988). Mating behavior of the marine copepod Othona davisae. Mar. Biol. 99: 39-45

Uye, S., Takamatsu, K. (1990). Feeding interactions between planktonic copepods and red-tide flagellates from Japanese coastal waters. Mar. Ecol. Prog. Ser. 59: 97-107

Van Alstyne, K. L. (1986). Effects of phytoplankton taste and smell on feeding behavior of the copepod Centropages hamatus. Mar. Ecol Prog. Ser. 34: 187-190

Wainwrght, P. C. (1991). Ecomorphology: experimental functional anatomy for ecological problems. Am. Zool. 31: $680-693$

Wallén, P., Carlsson, K., Liljeborg, A., Grillner, S. (1988) Three-dimensional reconstruction of neurons in the lamprey spinal cord in whole-mount, using a confocal laser scanning microscope. J. Neuroscl. Meth. 24: 91-100

Yoshikami, D., Okun, L. M. (1984). Staining of living presynaptic nerve terminals with selective fluorescent dyes. Nature 310:53-56

Zaitseva, O. V., Shuvalova, N. E. (1988). Morphological properties of neuron RPD1 in Lymnaea stagnalis and its involvement in processing of polymodal sensory information. Neurophysiology 20:571-577

Manuscript first received: April 17, 1993

Revised version accepted: July 20, 1993 